\title{
ELECTRONIC COMPONENTS EXPOSED TO NUCLEAR RADIATION IN ITER DIAGNOSTIC SYSTEMS: CURRENT INVESTIGATIONS AND PERSPECTIVES
}

\author{
Vincent Martin ${ }^{1}$, Luciano Bertalot, Jean-Marc Drevon, Roger Reichle, Stefan \\ Simrock, George Vayakis, Michael Walsh \\ ITER Organization / Bertin Technologies \\ Route de Vinon sur Verdon, Saint Paul Lez Durance, France / 155, rue Louis-Armand - CS 30495, 13593 \\ Aix-en-Provence, France \\ E-mail: Vincent.Martineiter.org
}

\section{Jens Verbeeck, Ying Cao}

KU Leuven, Division LRD-MAGyICS

Kasteelpark Arenberg 10, Heverlee 3001, Belgium

E-mail: Jens.Verbeeck@esat.kuleuven.be

\section{Marco Van Uffelen}

Fusion for Energy

Torres Diagonal Litoral B3, Josep Pla 2, 08019 Barcelona, Spain

E-mail:Marco.VanUffelenef4e. europa.eu

The ITER diagnostics systems will have sensors (e.g. cameras, detectors) and signal conditioning electronic components (e.g. preamplifiers) located in the Tokamak building and in particular in the port-cell area. These components will be exposed to gamma and neutron fluxes from the plasma, from the activated water circulating in the pipes of the water cooling system and from the cask transporting activated components during maintenance operation. Potential damage caused by the nuclear radiation range from function degradation (e.g. signal corruption) to component destruction. Neutronic calculations show that the total ionizing dose and neutron fluence are higher than what commercial components can withstand. In this context, an expert study for the selection of tolerant electronic components for the ITER diagnostic systems has been recently carried out. This paper is based on the outcome of this report. First the different options to mitigate radiation effects are reviewed and assessed according to the draft ITER policy presently under discussion on electronic exposed to nuclear radiation. Next, several options are elaborated based on the requirements for individual diagnostic systems (e.g. magnetics, neutronics, bolometers) with main focus on preamplifiers, ADCs and optical converters. The options include proposal of available commercial off-the-shelf components with shielding, or components already qualified for radiation hard environment (e.g. for space applications), or development of custom components. Evaluation criteria include availability, integration issues, cost, as well as development effort in case of a special development option is taken.

\footnotetext{
${ }^{1}$ Speaker
} 
First EPs Conference on Plasma Diagnostics - $1^{\text {st }}$ ECPD

14-17 April 2015,

Villa Mondragone , Frascati (Rome) Italy

The views and opinions expressed herein do not necessarily reflect those of the ITER Organization 


\section{Introduction}

The ITER diagnostics systems will provide accurate measurements of the plasma behaviour and performance. Measurements will be used for different operational roles ranging from real time machine protection to physics understanding. Most of these systems will have active sensors (e.g. cameras, detectors) and signal conditioning electronic components (e.g. preamplifiers) located in the Tokamak building including the port-cell area. Signal processing will be performed on fast controllers located in the diagnostic building. Figure 1 shows the cross-section of the general layout of the Tokamak and diagnostic buildings with the location of the enclosures (cubicles) hosting the electronic components.

\subsection{Nuclear radiation in ITER environment}

These components will be exposed to gamma and neutron fluxes from the plasma, from the activated water circulating in the pipes of the water cooling system and from the casks that transport activated components during maintenance operation. Neutronic calculations show that the total ionizing dose and neutron fluence are higher than what commercial components can typically withstand and vary with the area.

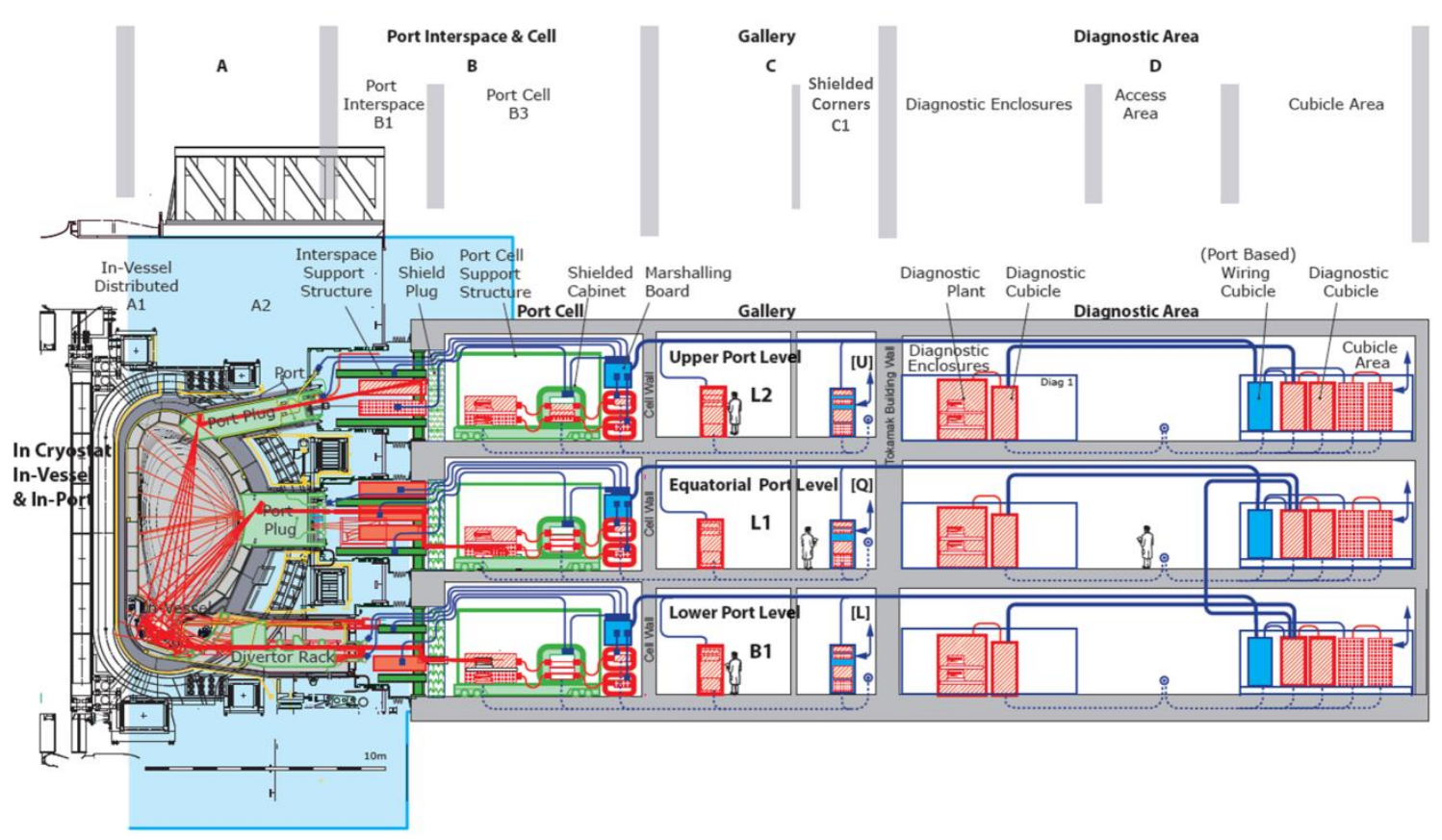

Figure 1 - Cross-section of the ITER Tokamak and diagnostic buildings showing the different considered areas. $^{2}$

In the left-side of Table 1 the different gamma doses of the ITER Tokamak complex are given, with on the right the expected neutron flux as a function of areas B3, C, C1 and D. Both are estimated, referring to Figure 1, in B3, C and D, which correspond to the port cell (B3), the gallery $(\mathrm{C})$, the shielded corners of the gallery $(\mathrm{C} 1)$ and the diagnostic building (D) area respectively. It is assumed that the accumulated gamma dose in the Gallery is a factor 100 less than the one in the Port cells. The accumulated gamma dose in the diagnostic area is assumed to

\footnotetext{
${ }^{2}$ The authors would like to acknowledge Chris Walker for the preparation of the picture. 
be 10 Gy or smaller (depending on the level in the ITER building). Work on estimation of neutron fluxes in the areas $\mathrm{C}, \mathrm{C} 1$ and $\mathrm{D}$ is on-going. The expectation is that these values are significantly lower than in the B3 area.

Table 1- Dose levelsand neutron flux in the different areas

\begin{tabular}{llll}
\hline & \multicolumn{4}{c}{ Accumulated dose estimates [kGy]* } \\
\hline Level & \multicolumn{3}{c}{ Area } \\
& B3 & C & C1, D \\
Lower ports (B1) & $\begin{array}{l}50-500(100 \\
\text { in average) }\end{array}$ & $0.5-5$ & 0.01 \\
$\begin{array}{l}\text { Equatorial ports } \\
\text { (L1) }\end{array}$ & $1-10$ & $0.01-0.1$ & $<0.01$ \\
Upper ports (L2) & $5-50$ & $0.05-0.5$ & $<0.01$ \\
\hline *Accumulated dose is for the ITER life of 4700 burn hours
\end{tabular}

\begin{tabular}{lll}
\hline \multicolumn{3}{c}{ Neutron flux estimates $\left[\mathbf{n} / \mathbf{c m}^{2} / \mathbf{s}\right]$} \\
\hline B3 & Area & \\
$10^{5}-10^{6}$ & C & C1, D \\
$10^{5}-10^{6}$ & low & low \\
$10^{5}-10^{6}$ & low & low \\
\hline
\end{tabular}

Potential damage caused by the nuclear radiation range from function degradation, e.g., data corruption in logical memories and drifts in analogue devices, to component destruction. These effects can appear progressively due to accumulated ionization or accumulated atomic displacements, or instantaneously, induced by an incoming neutron (the so-called single event upset). It is thus important first to list the diagnostic electronic components in order to assess the impact of nuclear radiation and then to elaborate a mitigation plan systematically.

\subsection{Diagnostics electronic components and mitigation approach}

Active electronics components of diagnostic systems exposed to nuclear radiation are represented in Figure 2.
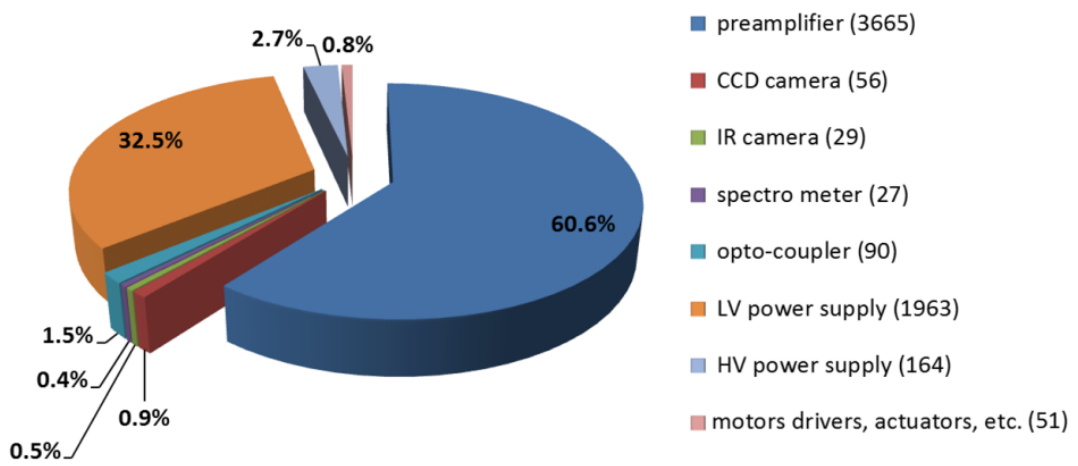

Figure 2- Provisional repartition of diagnostic electronic components exposed to nuclear radiation

Preamplifiers represent the majority of the components and are mainly used by magnetic systems to buffer the signals from the pick-up coils distributed in the vessel. Additionally, many electronic components in the port-cells (e.g. cameras, preamplifiers) require low voltage power supply (typically 12 VDC) that should be as close to the component as possible to avoid voltage drop and/or use of large section cables. Opto-couplers are also foreseen for many systems to decrease the amount of copper cables between the sensors located in the port-cells and the signal processing boards located in the diagnostic building and to avoid cable tray congestion.

An ITER policy on electronics exposed to nuclear radiation is presently under discussion [1] to prevent potential associated risks, by the mean of specific rules applicable to the 
procurement, installation and operation of electronics to be exposed to nuclear radiation in ITER. Alert thresholds above which a radiation mitigation strategy and/or a radiation qualification strategy are needed. For the diagnostics electronics components, which are considered to implement non-critical electronic functions, these thresholds have been proposed to be $1 \mathrm{kGy}$ for the accumulated dose and $100 \mathrm{n} / \mathrm{cm}^{2} / \mathrm{s}$ for the neutron flux.

If radiation qualification applies to radiation-tolerant or radiation-hardened components, the aim of radiation mitigation is to obtain mitigated radiation conditions as low as reasonably achievable. For non-radiation-tolerant components, a radiation mitigation strategy can be a combination of (by order of priority):

1. Permanent change of function(s) from active (with electronics) to passive (without electronics), and/or

2. Periodical replacements of the irradiated electronic component (in the absence of neutrons) when the cumulated radiation either (1) reaches the alert thresholds, or (2) reaches the maximum radiation conditions for which the component is qualified, and/or

3. Relocation of the electronic function in a remote area with no radiation or with harmless residual radiation, and/or

4. Local shielding ensuring a reduced or harmless residual radiation environment at the location of the electronic function.

\section{Trade-off analysis for typical diagnostic electronics components}

A trade-off analysis has been carried out to assess the potential mitigation options for three families of diagnostic systems: the magnetic, the neutronic (fission chamber, neutron flux monitor, neutron camera, neutron activation system) and the bolometer systems. This categorization relies on the study of the electronic requirement specifications of commonly used front-end electronics such as preamplifiers, ADCs and multiplexers. The trade-off analysis is based on a market survey of $\mathrm{COTS}^{3}$ components (non-radiation tolerant or hardened), space qualified components and custom development. Table 2 presents in a synthetic manner the results of this study based on the selection and availability of best applicable components (first column).

None of the COTS pre-amplifiers for magnetic systems show sufficient radiation tolerance if the components are located in the ports cells on both lower upper port levels. COTS preamplifiers are thus well-adapted if placed in the diagnostic building. This solution has been adopted for most of the magnetic systems. For neutronic systems, relocation in the galleries cannot be envisaged and Space qualified components do not meet electronic requirements. Therefore only local shielding or custom development are available as mitigation options.

The specified radiation levels (gammas) of the Space qualified components for signal conditioning (ADCs, multiplexers and optical links) have shown that most of the components meet the radiation requirement of galleries but none of them can be placed in the ITER port cells without local shielding.

\footnotetext{
${ }^{3}$ Commercial-Off-The-Shelf 
Table 2 - Synthesis table of trade-off analysis for typical candidate electronic components used by different diagnostic system families.

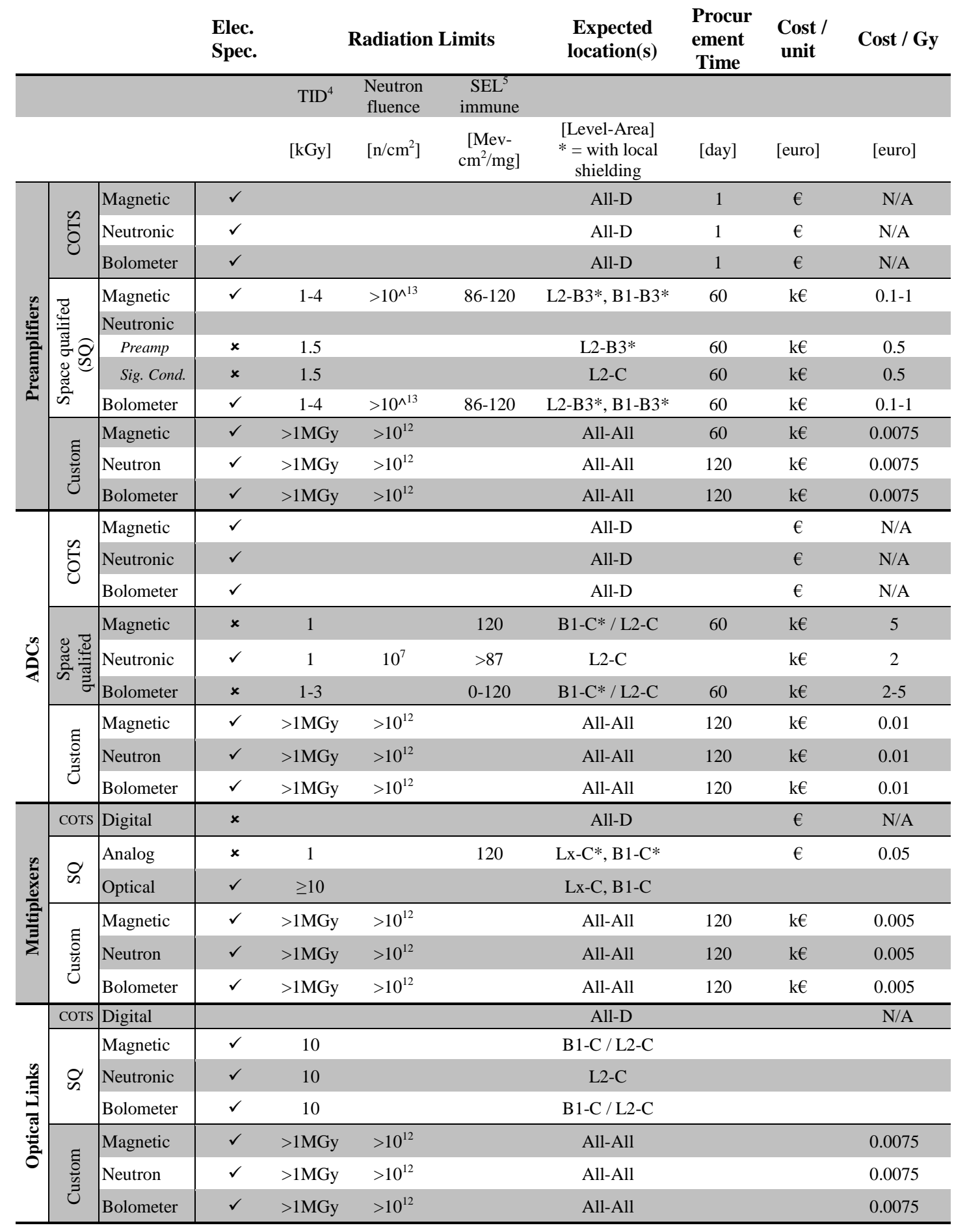

In all cases, custom development is an alternative offering several advantages: none or little shielding needed, adaptable architecture of the developed component to many applications and lower cost compared to Space qualified components (see Table 2). Moreover, a successful

\footnotetext{
${ }^{4} \mathrm{TID}=$ Total Ionizing Dose

${ }^{5} \mathrm{SEL}=$ Single Effect Latch up 
similar design has been achieved for ITER remote handling systems (see [2] for details) in a timely manner.

\section{Conclusion and Perspectives}

The front-end electronics of ITER diagnostic systems will be exposed to nuclear radiation. Such radiation can damage or destroy electronic components. A mitigation strategy is proposed to prevent these risks (see Table 3). Considering the large number of systems, a systematic market survey has been performed to assess the mitigation options if using COTS components, Space qualified devices or custom development for common electronic components such as preamps, ADCs, multiplexers and optical links. Table 3 summarizes the outcome of such investigation for magnetic, neutronic and bolometer systems and power supplies.

Table 3-Summary of mitigation plan for selected diagnostic electronic components

\begin{tabular}{lll}
\hline $\begin{array}{l}\text { Diagnostic system / } \\
\text { component }\end{array}$ & $\begin{array}{l}\text { Initial front-end electronic } \\
\text { architecture / location }\end{array}$ & Mitigation plan \\
\hline Magnetic & All preamps in the port-cells & $\begin{array}{l}\text { 1- Passive resistors in the port-cells for some } \\
\text { magnetic systems + } \\
\text { 3- First electronic stage in the diagnostic building }\end{array}$ \\
\hline Neutronic detectors & $\begin{array}{l}\text { All preamps in the port-cells } \\
\text { with local shielding }\end{array}$ & $\begin{array}{l}\text { 4- Local shielding or } \\
\text { x - Rad hard custom preamps in the port-cells }\end{array}$ \\
Bolometer & $\begin{array}{l}\text { Preamps and signal } \\
\text { conditioning unit (SCU) in the } \\
\text { port-cells }\end{array}$ & $\begin{array}{l}\text { X - Custom /rad hard preamps in the port-cell } \\
\text { 4- Relocation of SCU in the galleries }\end{array}$ \\
\hline $\begin{array}{l}\text { Power supplies of all } \\
\text { systems }\end{array}$ & $\begin{array}{l}\text { In the port-cells with shielding } \\
\text { or in the diagnostic building }\end{array}$ & 4-Relocation in the gallery shielding corners \\
\hline
\end{tabular}

Mitigation option (1), passive front ends, is only possible for a limited number of cases. Option (2), periodic replacement was found generally unsuitable because of ALARA principles for personnel exposures. When relocation (Option 3) is also not possible, local shielding is envisaged but may imply integration issue considering the volume and the weight of such enclosures. Rationalization efforts are then planned to design and integrate a shielded enclosure to host preamplifiers of different systems in a port-cell.

Radiation tolerant custom development reduces the shielding and maintenance complexity and is thus a promising option (e.g. preamplifiers in the port-cell area) or for integrated signal conditioning unit (e.g. for bolometer). Further tests are needed to assess the tolerance to neutron radiation. The procurement strategy for these non-critical electronics shall be also carefully elaborated to ensure maintenance, obsolescence management and overall cost-efficiency.

Finally, further studies shall be carried out for the specific case of mitigation plan for cameras (CCD, infrared) that are difficult to relocate and for which, in addition to the problems identified above, is also not cost-efficient.

\section{References}

[1] Jens Verbeeck, et al, Qualification method for a 1 MGy-tolerant front-end chip designed in $65 \mathrm{~nm}$ CMOS for the read-out of remotely operated sensors and actuators during maintenance in ITER, Fusion Engineering and Design, in press (2015).

[2] M. Dentan, Draft ITER policy on electronics exposed to nuclear radiation ITER IDM, Private communication. 